\title{
Between territories and domains: an ESP-oriented enquiry in the borders
}

Course development, genre analysis, and the role of ESP in education

\section{Helen Basturkmen}

\section{(2) OpenEdition \\ Journals}

\section{Electronic version}

URL: http://journals.openedition.org/asp/3815

DOI: $10.4000 /$ asp.3815

ISSN: 2108-6354

\section{Publisher}

Groupe d'étude et de recherche en anglais de spécialité

\section{Printed version}

Date of publication: 1 November 2013

Number of pages: 17-21

ISSN: 1246-8185

Electronic reference

Helen Basturkmen, "Between territories and domains: an ESP-oriented enquiry in the borders », ASp [Online], 64 | 2013, Online since 01 November 2014, connection on 02 November 2020. URL : http:// journals.openedition.org/asp/3815; DOI : https://doi.org/10.4000/asp.3815

This text was automatically generated on 2 November 2020 .

Tous droits réservés 


\title{
Between territories and domains: an ESP-oriented enquiry in the borders
}

Course development, genre analysis, and the role of ESP in education

\author{
Helen Basturkmen
}

\section{Introduction}

1 The Call for Papers for the 34th GERAS International Conference identified key themes for presentations. One theme concerned the need to mark out the territories traditionally explored in ESP. In other words, the Call suggested discussion of the territories that have conventionally been addressed in ESP-oriented enquiry. Teaching, discourse and culture were identified as areas of enquiry. Whereas the first theme suggested a need to consider the current and past situations, the second theme suggested a need to look ahead: this theme mentioned new frontiers and described ESP as stretching beyond traditional perimeters. A third theme described ESP as an 'interface' discipline that can draw on several approaches. A further theme identified a set of foci in ESP.

2 The present paper addresses these themes by reviewing conventional enquiry in teaching and discourse areas and by highlighting emerging topics. The latter is illustrated with reference to three of the writer's recent research projects which show how research can span different areas, for example, enquiry into teaching which involved enquiry into discourse, and an ESP study involving all three areas (teaching, discourse and culture) referred to in the Call for Papers. Figure 1 shows a representation of the three areas of enquiry and the borders between them. 


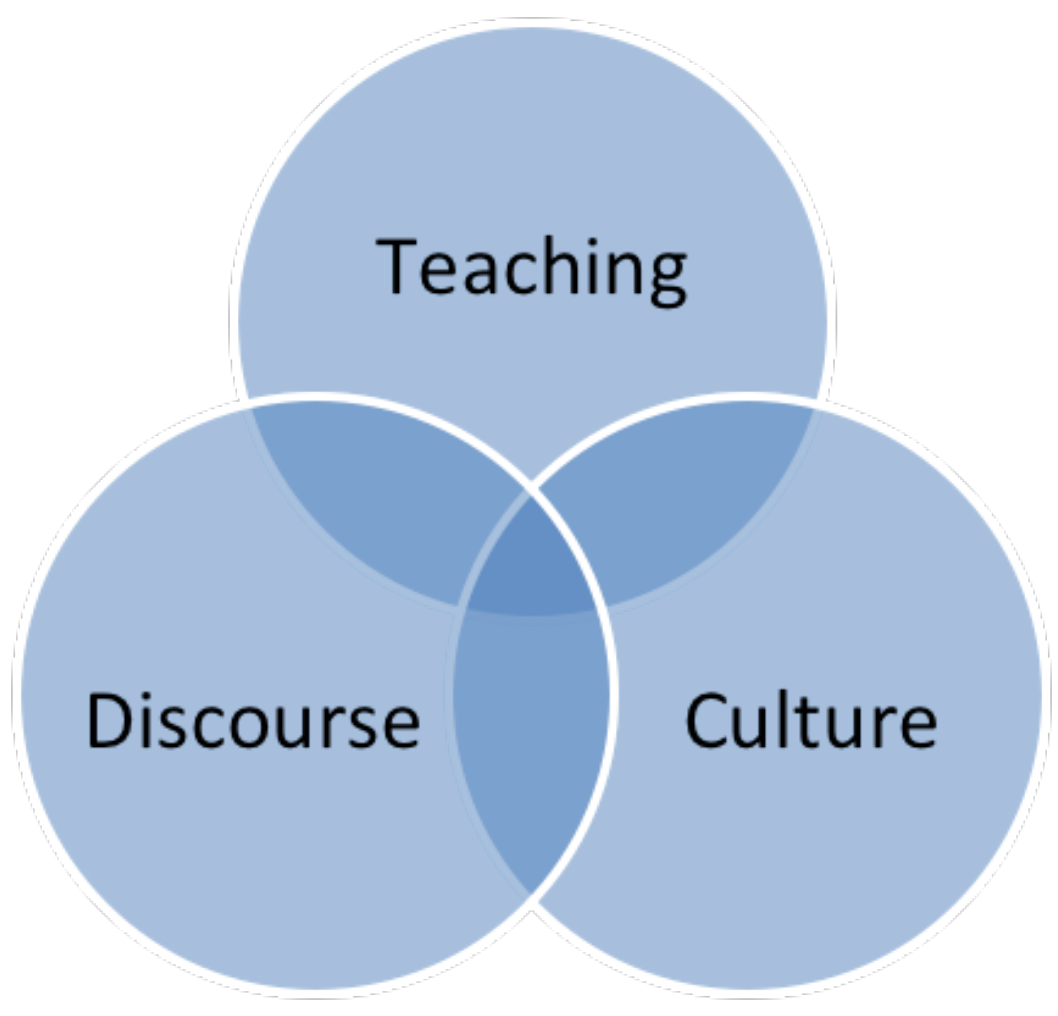

\section{Teaching}

\subsection{Conventional focus of enquiry}

Teaching has been at the centre of ESP since its beginnings. One description of ESP that appeared in the late 1990's characterised ESP as an "essentially materials- and teaching-led movement" (Dudley-Evans \& St John 1998: 19). It is debatable whether this characterisation reflects the current situation as well as the situation at the end of the 21st century: research seems to play an ever-increasing role in ESP. Nevertheless, few would argue that teaching and preparation for teaching, in particular the development of courses and materials to cater for students' needs, remains central to the work of many ESP teachers.

4 The key role of course and materials development is reflected in the number of articles and book chapters that have over the years provided descriptive accounts of how individual teachers and schools have set up courses for various disciplinary, professional or vocational groups in different geographical contexts. These articles and book chapters often include a description of the needs analysis that underpinned the development of the course. Works of this nature have been a conventional focus of enquiry in the ESP literature.

5 Articles by Cowling (2007) and Tsuda (2012) illustrate this topic in the ESP literature. Both studies were set in the Japanese context and whereas the first study concerned English for workplace needs, the second concerned English for study needs. Cowling (2007) reports the development of a syllabus for intensive workplace courses at an industrial company. The report provides a detailed description of the needs analysis, 
including the different methods that were used to gather information to inform the development of the course (a set of intensive modules for a Business English communication course for new employees). The article reports how a course specifically designed to address the needs of the new employees was not possible as the new employees neither had positions in the company nor knew exactly which positions they would be given. Determining needs was thus particularly challenging and required the course developer to devise multiple methods and to draw on multiple sources for information.

6 Tsuda (2012) reports the development of a course and materials for an ESP course for dieticians in a postgraduate college. As ESP for dieticians was not an established area of ESP, previous research or existing course descriptions and materials could not be located. The article reports the initial stage of needs analysis to gain an overall understanding of the work and communicative needs of dieticians (for example, one need was to provide nutrition counselling for English-speaking patients in hospital settings). It also reports how the teacher/course developer collaborated with subject specialists to devise the course and projects for the students.

7 The studies such as those described above and the many other reports of the development of courses and materials in particular settings and for different groups of learners have been and will continue to be of great importance to ESP. There are a number of reasons why this is so. The studies represent practitioner-led enquiry: enquiry arising in response to the demands of a particular teaching situation. The reports have resonance for other teachers and course designers. The reports have been through a process of review and the studies have been selected as strong examples of quality teaching and course development practices. They often offer innovative solutions to real-world problems (for example, how to develop a course in a new area of ESP). ESP teachers in different settings may face similar challenges and the solutions pioneered and reported in the studies could be adapted.

\subsection{A further area of enquiry - between the borders of teaching and discourse}

ESP literature on the topic of course development in teaching has conventionally tended to focus on the courses and materials developed for particular groups of learners. The study reported below represents a departure: it deals with the processes involved in course development across situations. It reports the research project on which the book Developing Courses in English for Specific Purposes (Basturkmen 2010) was based. The paper focuses in particular on one part of the project, namely, the part that investigated how the ESP teacher research participants investigated and described discourse when designing their courses and materials. The study as a whole centres on teaching (the work teachers do in developing ESP courses) and would thus be situated in the didactic territory shown in Figure 1. However, the part of the study that concerned how the teachers investigated and described discourse would be situated in the interface between two territories in Figure 1, namely, teaching and discourse.

9 The study as a whole was an enquiry to try to identify the processes that experienced ESP teachers/course developers used to design a specific course. It drew on Johnson's (2003) definition of research into expertise, namely, an investigation into the procedures experts use when faced with a real world situation. The study examined the 
processes teachers/course developers used in developing a particular ESP course, a course which they had fairly recently developed. It aimed to explicate their objectives (what they hoped to achieve and felt was important in ESP course development) and also the constraints they faced when developing the course. The study's aims were to examine how a small number of teachers set about developing a particular course, and to identify what the teachers' main considerations had been and the nature of any constraints they faced in the process of developing the courses.

Why might an investigation of the processes involved in developing ESP courses and materials be of value? Course and materials development are often major elements in the work of ESP teachers. According to Belcher (2006: 135), "ESP specialists are often needs analysts first and foremost, then designers and implementers of specialised curricula." In other words, ESP teachers typically have course and materials development as an intrinsic element of their work. Teachers of general English often have a wide range of high quality commercially-produced course books that they can use or base their courses on. This is much less often the case in ESP where the teacher may need to develop different courses for different needs and subject areas and where the specific needs of the leaners may only tangentially match the content in published course books, even course books on seemingly relevant topics such as English for Engineering or Nursing. The fact that course and materials development are such major elements in the work of the ESP teacher has implications for ESP teacher development. Findings from research of how experienced ESP teachers develop courses and materials can be used to inform teacher development programmes.

11 The study's approach had three key features. Firstly, as stated above, it was a study of expertise. Thus the research participants (the teachers/course developers in the study) were highly experienced ESP teachers who were acknowledged in their school or institution as having successfully developed courses to meet specific needs. Secondly, the study focused on the processes the teachers used when faced with a real-world situation. Thus the researcher asked the teachers about a course they had recently developed: the focus was on the development of a specific course. The teacher participants were asked to describe actual events and decisions. In this way they described and explained what they had done in relation to concrete examples and experiences. The research tried to avoid the situation where research participants would talk generally or in the abstract and suggest an idealised version of course development. Thirdly the design was a cross-case study. It investigated processes across four different and varied ESP courses. It was an example of what is termed in the research methodology an instrumental or collective case study (Stake 2000; Casanave 2010). Unlike intrinsic case study research in which the researcher is primarily interested in the particulars of a case or cases, in an instrumental case study the researcher investigates the cases with a primary interest in understanding a phenomenon or general condition.

Individual cases in the collection may or may not be known in advance to manifest some common characteristics [...]. They are chosen because it is believed that understanding them will lead to a better understanding, perhaps even theorising about a still larger collection of cases. (Stake 2000: 437)

There were four cases in the study, two of which were courses in English for workplace needs and two of which were courses in English for study needs. All of the cases were in the New Zealand context. The first case was a course developed for a group of experienced medical doctors who had immigrated to New Zealand. The doctors were on 
a professional development course leading to a registration examination to enable them to gain registration to work in the country. The English course focused on one particular communicative event of key significance to the work of doctors, the doctorpatient consultation. The course needed to prepare the doctors for a patient-centred form of consultation: the doctors' performance in such consultations constituted one area of assessment in the registration examinations. The purpose of the English course was to support the doctors' language development by focusing on the 'subtle' use of language, the New Zealand variety of English, the informal New Zealand register and the precise communication skills required in patient-centred consultations. The second course was a language and communications course for during-experience police recruits. This was a wide-spectrum course that focused on both written and spoken language needs of the recruits. The third course was English for Specific Academic Purposes. It was a course in English for Art History that had been devised for preexperience students in a tertiary education setting. The fourth course was English for General Academic Purposes. It was a series of thesis writing preparation seminars for students from a mix of disciplines in the same tertiary education setting.

The study methodology included interviews with the teachers/course developers. In each case, the course developer was also the teacher of the course and in one case two teachers together developed and taught the course. The methodology also included document analysis (course descriptions, instructional materials, needs analysis documents) and elicitation of the teachers/course developers' reflections on the processes and considerations involved in developing the course.

For example, the teachers/course developers were asked to reflect on how they had investigated and described specialist discourse in preparing the course and their instructional materials. This line of enquiry revealed that in all four cases the teachers had collected raw data/language samples and analysed them, that in some cases, the teachers/course developers had been able to locate and use existing data and descriptions of specialist discourse and that locating sources of existing data/ descriptions had been difficult, especially at the outset of the course. The enquiry also found that collecting raw data and investigating specialist discourse had been timeconsuming but so had the search for available descriptions. These findings have potential implications for ESP teacher education. For example, teacher training for ESP teachers could include content on ways to locate and search existing language sources and data. A full account of findings can be found in the original work.

\section{Discourse}

\subsection{Conventional area of enquiry}

15 One conventional focus of enquiry into discourse in ESP has been description of genres in workplace or study situations. The descriptions produced are often used to develop instructional materials for writing. ESP genre researchers have tended to draw on the approach to analysis developed by Swales $(1990,2004)$ and the approach developed by Swales has become known as the English for Specific Purposes genre tradition (Burns 2012). The approach generally includes investigation of context (how the genre is used and its purposes in the target discourse community) and a linguistic analysis (investigation of the genre's rhetorical structure in terms of moves and steps and 
sometimes analysis of grammatical and lexical features as well). The descriptions resulting from such research have had great importance for ESP, especially English for Academic Purposes - largely, I would argue, because they offer novices in a profession or discipline the (often tacit) knowledge that established members have about the rhetorical organisation of the genres they use in their work or study. Genre analysis enables what Nesi and Gardner (2011: 262) refer to as the "explication of the tacit knowledge that the initiated possess."

16 The ESP literature contains a good number of studies that have investigated a genre in a particular discourse community. One example is Lim's (2006) study of the methods section in research articles in management. This study would be of great interest to members of the Management academic discourse community and we expect of particular interest to novice researchers or those writing an article in this discipline for the first time.

\subsection{A further area of enquiry - between the borders of discourse and culture}

Recent years have seen the emergence of a number of studies that have taken as their focus the topic of variation in the practice of a genre across two or more discourse communities. The communities may be different linguistic and cultural settings or different disciplines, as in the study reported below. Such comparative genre-based studies enquire into the similarities or differences in the practice of a genre across discourse communities. This search for possible variation in a genre tends to use quantitative means to establish differences. As genre analysis is investigation of discourse in types of texts and as the studies compare the practice of the genre in different communities or disciplines, that is, cultures, this line of enquiry can be situated in the border between the areas of discourse and culture shown in Figure 1. It can be illustrated with reference to a recent study I conducted which investigated the discussion of results sections of research articles in two disciplines (Basturkmen 2012). The study, an enquiry into disciplinary variation in research reporting, examined how results of research were presented in published articles in two very distinctive disciplines and discussed the differences observed in relation to research traditions and values. Discussion of results sections from published research articles in Dentistry were compared to findings of earlier research into discussion of results sections in Applied Linguistics (Basturkmen 2009). Both studies focused in particular on the analysis of one key move, the commenting on results move, a significant feature of discussion of results sections.

18 The study of Applied Linguistics discussions had suggested a four-move framework (background information, summarising results, reporting a particular result and commenting on the result) and found different writers used any combination of three steps to realise their commenting on the result moves (explaining the result, comparing the result to the literature and evaluating the result). It had also found that the main means by which writers in Applied Linguistics had developed their discussions was through the use of explaining and that they frequently used alternative explanations.

19 The second study (Basturkmen 2012) found that although the discussion sections in Dentistry could largely be accounted for in terms of the framework suggested by the earlier study, there were important quantitative differences. The step explaining the 
result, which had been highly prevalent in the Applied Linguistics data, occurred in only around half the commenting moves in the data from Dentistry, and the use of alternative explanations was far less frequent too. It was argued that such differences might reflect varying research traditions in the two disciplinary cultures. In Applied Linguistics there is not a prevailing research tradition and researchers may call on different theoretical paradigms to offer alternative explanations or perspectives on findings.

\section{Culture}

The final study described in the paper is one that is still in progress. It is set in a tertiary education institution. This study has taken my co-researcher and me into a different cultural setting (first-year Accountancy classrooms) than we are used to (we are more familiar with language teaching classrooms) and in trying to understand Accountancy classroom discourse. This study therefore can be situated in the interface between all three areas shown in Figure 1.

The study came about as a response to a request for a consultative role for an ESP/ language specialist. Business Studies is an important subject in this institution and each year many students from the local context, including many for whom English is an additional language, take courses in this subject. In the near future some of the courses will be provided off-shore, in Mainland China. For these reasons the Business faculty wishes to develop an understanding of the linguistic demands that studying the subjects may present to students, especially those for whom English is not a first language, and have approached an English language/ESP specialist for consultation. Before making suggestions as to what subject lecturers should do or what strategies they could use to facilitate language difficulties, we wished to first understand what strategies subject lecturers may already be using to help students with language. My co-researcher and I therefore decided to observe classes and at this point we have observed the classes of one lecturer of accountancy.

2 The study uses observation (we have observed, recorded and transcribed classes) and an interview (we have interviewed the Accountancy lecturer whose classes we have observed). The interview used semi-structured questions and stimulated recall, a technique used in the field of Second Language Acquisition to elicit a person's retrospective account of his or her thinking during a past event (Mackay \& Gass 2005).

23 Observations and analysis of the transcripts have shown that both the lecturer and students periodically initiate time-outs from discussion of Accountancy content to focus on language issues. We have therefore used the construct of Language-Related Episodes (LREs) (Swain \& Lapkin 1998: 326) from the Second Language Acquisition literature to investigate these time-outs during the classes, that is, the episodes when talk focused on language. The following excerpt is taken from part of a lesson when there was lecturer-fronted teaching. The lecturer was reviewing the students' responses to questions on an accountancy task which they had prepared earlier.

This excerpt shows an episode initiated by the lecturer. The episode focuses on the meaning of "cash flow varies." The lecturer appears to be clarifying the meaning of this expression for the benefit of students in the class. He directs attention to the meaning of the expression and provides a synonym for it not because any communication problem has occurred but because he is using the opportunity that the student's use of 
the expression (what triggers the episode) has provided to highlight an aspect of language use in Accountancy. In the interview following the observations, the lecturer talked about his strategy of familiarizing students with the idea that accountants often use different terms to refer to "exactly the same thing."

Example episode

Lecturer: Now remember with this you can't make the shortcut method. Why can't you take the shortcut method?

Student: The cash flow varies.

Lecturer: Right the cash flow varies. They go up and down each year. So you have to do the cumulative table. So if you do it for the first two years, you know at the end of year two you've become positive.

Findings at this time are preliminary as the study is not yet complete. These preliminary findings show that LREs occurred quite frequently in the Accountancy classroom and that most episodes were initiated by the lecturer (rather than the students), thus suggesting that in this first-year Accountancy classroom attention was periodically drawn to language issues.

To date, most ESP work (published work at least) has shown the role of the ESP specialist as preparing students for the linguistic demands of their target situations. In other words, the role has largely been construed in terms of direct teaching. The preliminary findings from the project described above suggest that subject lecturers may incorporate a focus on language within subject teaching. This leads us to suggest a consultative role for the ESP specialist. For example, it might be possible for the ESP specialist to discuss further ways of highlighting discipline-specific vocabulary within the context of content teaching. The Accountancy lecturer described above endeavoured to raise his students' awareness of the use of terms and words in Accountancy. An ESP specialist, drawing on the rich literature from Language Teaching could suggest further ways that vocabulary can be highlighted. Rather than the ESP specialist directly teaching English for Accountancy, an alternative role of working with subject lecturers may be possible.

\section{Conclusion}

The Conference Call for Papers asked participants to consider the areas of ESP enquiry and how the traditional perimeters of enquiry can be extended. The Call identified three broad areas of ESP interest, teaching, discourse and culture. The Conference theme thus provided an opportunity for ESP practitioners to stand back from their current teaching and research in order to examine the wider picture (the three areas) and consider where their work is situated. This paper reviewed some of the conventional topics of enquiry in the teaching and discourse areas. It was argued that topics centrally concerned with teaching, such as description of needs, courses and materials for particular groups of students and topics centrally concerned with discourse, such as the analysis of genres used in particular disciplines or professions, have been and will continue to be of major importance to the field. However, the paper also argued that new topics and approaches to enquiry are emerging. To illustrate this, three recent research studies were introduced. The studies involved topics situated in the borders between the three areas and which draw in part on methods which have been little reported in the ESP literature to date (such as an extrinsic case study approach and stimulated recall). As a conclusion, the two means of extending ESP 
enquiry and moving beyond traditional perimeters are by focusing research on the interfaces between teaching, discourse and culture and by drawing on diverse research methods.

I would like to express my gratitude to Anthony Saber of ENS Cachan and the GERAS Executive for inviting me to the 34th GERAS Conference. I am grateful for the warm welcome and help I was shown during my stay.

\section{BIBLIOGRAPHY}

Basturkmen, Helen. 2009. "Commenting on results in published research articles and masters dissertations in language teaching". Journal of English for Academic Purposes 8, 241-251.

Basturkmen, Helen. 2010. Developing Courses in English for Specific Purposes. Basingstoke: Palgrave Macmillan.

Basturkmen, Helen. 2012. "A genre-based investigation of discussion sections in research articles in dentistry and disciplinary variation”. Journal of English for Academic Purposes 11/2, 134-144.

Belcher, Diane. 2006. "English for specific purposes: Teaching to perceived needs and imagined futures in worlds of work, study and everyday life". Teaching English to Speakers of Other Languages Quarterly 40, 133-56.

Burns, Ann. 2012. “Genre and genre-based teaching”. In Byram, M. and A. Hu (eds.). Routledge Encyclopedia of Language Teaching and Learning. New York: Routledge, 269-274.

Casanave, Christine Pearson. 2010. “Case studies”. In Paltridge, B. \& A. Phakiti (eds.), Continuum Companion to Research Methods in Applied Linguistics. London: Continuum, 66-79.

Cowling, Jeremy. 2007. "Needs analysis: Planning syllabus for a series of intensive workplace courses at a leading Japanese company". English for Specific Purposes 26, 426-42.

Dudley-Evans, Tony and Maggie St John. 1998. Developments in English for Specific Purposes. Cambridge: Cambridge University Press.

Johnson, Keith. 2003. Designing Language Teaching Tasks. Basingstoke: Palgrave Macmillan.

Lim, Jason. 2006. "Method sections of management research articles: A pedagogically motivated qualitative study". English for Specific Purposes 25, 282-309.

Mackay, Alison and Susan Gass. 2005. Second Language Research: Methodology and design. Mahwah, NJ: Lawrence Erlbaum Associates.

Nesi, Hilary and Sheena Gardner. 2012. Genres across the Disciplines: Student writing in higher education. Cambridge: Cambridge University Press.

Stake, Robert. 2000. “Case studies”. In Denzin, N.K. and Y.S. Lincoln (eds.), Handbook of Qualitative Research (2 ${ }^{\text {nd }}$ edition). London: Sage Publications, 435-454.

Swain, Merril and E. Lapkin. 1998. "Interaction and second language learning: Two adolescent French immersion students working together". The Modern Language Journal 82, 320-337. 
Swales, John. 1990. English in Academic and Research Settings. Cambridge: Cambridge University

Press.

Swales, John. 2004. Research Genres: Exploration and applications. Cambridge: Cambridge University Press.

Tsuda, Akiko. 2012. "Developing an ESP course and materials for dieticians". Journal of IATEFL ESP Special Interest Group 39, 23-30.

\section{ABSTRACTS}

The paper focuses on the three areas of ESP theory and research that were identified in the call for papers for the 34th GERAS Conference, namely, teaching, discourse and culture. It reviews some conventional foci of ESP-oriented enquiry in these areas. However, the main focus of the paper is on the borders between individual areas. Three of the author's recent research studies are introduced. These are studies on the topics of course development processes, genre analysis and language issues in disciplinary teaching. It is argued that each of these three studies could be situated in the borders between teaching, discourse and culture. The Call for Papers drew attention to the fact that the traditional study perimeters of ESP are being extended. This paper suggests that research in the borders between traditional topic areas and the use of less familiar methodologies are ways that the scope of ESP-oriented research can be extended.

L'article s'articule autour des trois axes qui sous-tendent la théorie et la recherche en anglais de spécialité figurant dans l'appel à communications du $34 \mathrm{e}$ colloque du GERAS, à savoir la didactique, le discours et la culture. Il passe en revue certains domaines de recherche traditionnels en anglais de spécialité selon ces axes ; cependant, l'objectif principal de l'article porte sur les frontières entre les axes. L'auteur présente trois études qu'elle a récemment menées et qui traitent des thèmes suivants : les processus de conception de cours, l'analyse de genre et les problèmes langagiers dans un enseignement disciplinaire. Cet article avance que chacune de ces trois études pourrait se situer à la frontière de la didactique, du discours et de la culture. L'appel à communications mettait l'accent sur le fait que le périmètre traditionnel d'analyse de l'anglais de spécialité s'élargit. Cet article suggère que la recherche aux frontières des thèmes traditionnels et que l'utilisation de méthodologies moins conventionnelles fournissent un moyen d'élargir le champ de recherche en anglais de spécialité.

\section{INDEX}

Mots-clés: axe, domaine de recherche, frontière, thème émergent Keywords: area, border, emerging topic, focus of enquiry

\section{AUTHOR}

\section{HELEN BASTURKMEN}

Helen Basturkmen is a Senior Lecturer at the University of Auckland, New Zealand where she convenes MA courses in discourse analysis, ESP and research methodology, and undergraduate courses in Language Teaching. Her research interests include the study of discourse features of written text in research reports, feedback on student writing in dissertations and theses, pragmatics, ESP/EAP course development processes and disciplinary differences in academic 
writing. She has published articles in a number of international journals and has served as assistant editor on the journal Language Teaching Research and as an editorial review board member of the Journal of English for Academic Purposes and New Zealand Studies in Applied Linguistics. She has written two books on English for Specific Purposes (Lawrence Erlbaum 2006, Palgrave Macmillan, 2010). h.basturkmen@auckland.ac.nz 